\title{
Another step toward successful mechanical support of neonatal patients with single-ventricle circulation
}

\author{
Ryan R. Davies, MD
}

\footnotetext{
From the Department of Cardiovascular and Thoracic Surgery, UT Southwestern Medical Center and Children's Health, Dallas, Tex.

Disclosures: Author has nothing to disclose with regard to commercial support.

Received for publication May 8, 2018; revisions received May 8, 2018; accepted for publication May 9, 2018; available ahead of print June 23, 2018.

Address for reprints: Ryan R. Davies, MD, 1935 Medical District Dr, MC B3.410, Dallas, TX 75235 (E-mail: ryan.davies@utsouthwestern.edu).

J Thorac Cardiovasc Surg 2018;156:e175-6

$0022-5223 / \$ 36.00$

Copyright (C) 2018 by The American Association for Thoracic Surgery

https://doi.org/10.1016/j.jtcvs.2018.05.022
}

Mechanical support of single-ventricle patients remains challenging. This is particularly true of those at the first stage of palliation with parallel pulmonary and systemic circulations and ductal (or shunt) dependence. The initial report of the Berlin Heart EXCOR (Berlin Heart GmbH, Berlin, Germany) experience in these patients was dismal, with only 1 out 9 supported patients surviving beyond 17 days. ${ }^{1}$ Extracorporeal membrane oxygenation remains in common use, but the likelihood of survival to transplant beyond 30 days approaches zero. ${ }^{2}$ Better options are needed.

The report from Maeda and colleagues ${ }^{3}$ in this issue of the Journal may provide 1 option. The authors successfully supported a patient with hypoplastic left heart syndrome and right ventricular dysfunction for more than 4 months. Central to the success was the ability to provide the high pump output necessitated by parallel circulations. Throughout support, the pump delivered a cardiac index in excess of $5 \mathrm{LPM} / \mathrm{m}^{2}$. As the authors note, a $10-\mathrm{mL}$ Berlin Heart pump would have to pump at $110 \mathrm{bpm}$ to meet the minimal flow under optimal conditions. In contrast, use of an oversized pump would result in a stroke volume excessive for a patient of this size. Continuous-flow pumps may also be more responsive to minute-to-minute changes in pulmonary and systemic vascular resistance with minimization of pulmonary overcirculation or excessive pulmonary venous pressure. These clinical reports, ${ }^{3,4}$ along with computer modeling, ${ }^{5}$ suggest that continuous-flow pumps should be preferred over pulsatile pumps in single-ventricle patients with parallel circulations.

Despite excellent flow rates and no neurologic complications, the patient faced significant morbidity: Possible necrotizing enterocolitis with the inability to tolerate enteral feeds, severe hemolysis during initial implant, acute kidney injury, and venous congestion resulting in pulmonary edema. Some of these problems were

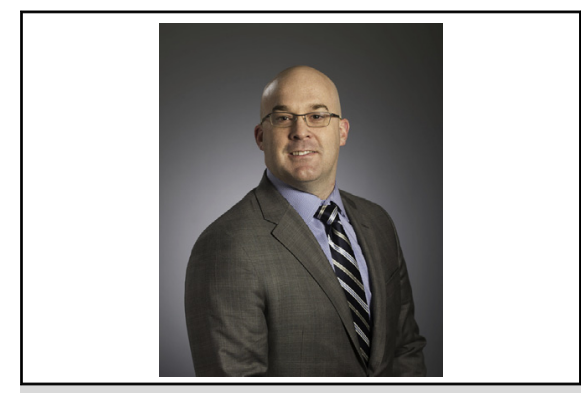

Ryan R. Davies, MD

Central Message

Continuous-flow ventricular assist devices can successfully bridge neonates with singleventricle physiology and parallel circulations to heart transplant.

See Article page e171.

mitigated by high pump flows, but the complications confirm that the use of mechanical support in small single-ventricle patients is much higher risk than durable support in older patients. Although the authors were able to close the sternum at the initial operation, in smaller patients-especially those under $3 \mathrm{~kg}$ - sternal closure (and therefore liberation from mechanical ventilation) may not be possible. Thus, the threshold for initiation of mechanical support in single-ventricle neonates needs to be higher than in larger children or those with cardiomyopathy.

Finally, it should be noted that this is a report of a singular success. Other patients, with slightly different physiology (lower pulmonary vascular resistance or a larger ductus) might not have fared as well. Further implants with reports of both successes and failures are required to advance the field. However, Maeda and colleagues ${ }^{3}$ should be congratulated on their success because this is 1 more step forward toward the eventual goal of providing routine, uncomplicated, mechanical support to neonates with failing singleventricle circulations.

\section{References}

1. Weinstein S, Bello R, Pizarro C, Flynn-Thompson F, Kirklin J, Guleserian K, et al The use of the Berlin heart EXCOR in patients with functional single ventricle. $J$ Thorac Cardiovasc Surg. 2014;147:697-705. 
2. Fraser CD, Jaquiss RDB, Rosenthal DN, Humpl T, Canter CE, Blackstone EH, et al. Prospective trial of a pediatric ventricular assist device. $N$ Engl J Med. 2012;367:532-41.

3. Maeda K, Yarlagadda VV, Rosenthal DN, Almond CS. Successful use of a ventricular assist device in a neonate with hypoplastic left heart syndrome with right ventricular dysfunction. J Thorac Cardiovasc Surg. 2018;154:e171-3.
4. Gazit AZ, Petrucci O, Manning P, Shepard M, Simpson K, Castleberry C, et al. A novel surgical approach to mechanical circulatory support in univentricular infants. Ann Thorac Surg. 2017;104:1630-6.

5. Schmidt T, Rosenthal D, Reinhartz O, Riemer K, He F, Hsia TY, et al. Superior performance of continuous over pulsatile flow ventricular assist devices in the single ventricle circulation: a computational study. J Biomech. 2017;52:48-54. 